\title{
Does the Institutional Context Shape International Operations Strategy? Country-Level Analysis
}

\author{
Vitor Fabian Brock \\ Unisinos \\ vitorbrock@unisinos.br \\ Iuri Gavronski \\ UNISINOS \\ igavronski@unisinos.br
}

\begin{abstract}
Recent literature has proposed that institutions play a pivotal role in corporate and business strategies. We argue that this role holds for manufacturing strategy as well. Despite extensive literature regarding international operations management $(\mathrm{OM})$, few studies verify how important variables in OM vary across different institutional contexts. This scarcity of comparative crosscountry research reveals an important gap both for research and practice. In this paper we address this gap by providing a data analysis of a recent survey collected in Canada and Brazil. We replicate and extend previous research by comparing important variables of manufacturing strategy in these two institutional contexts such as knowledge exchange, green process management, environmental supplier management and the traditional manufacturing performance dimensions.
\end{abstract}

Keywords: Operations Strategy; Green Supply Management; Sustainable Operations; Global Operations; Institutional Context. 


\section{INTRODUCTION}

Manufacturing is already a globalized economic activity and global manufacturing will be increasingly geographically dispersed. Forecasts from the Organization for Economic Cooperation and Development (OECD) predict that the global share of the gross domestic product (GDP) from developed countries will drop from $60 \%$ in 2000 to $43 \%$ by 2030 (Radjou \& Kaipa, 2010). This dispersion will require new capabilities and skills from operations managers. The field of operations management $(\mathrm{OM})$ has a long tradition in studying international OM (e.g., Chakravarty, Ferdows, \& Singhal, 1997; Roth, Gray, Singhal, \& Singhal, 1997). Most international OM literature, up to the year 2000, compared U.S. operations with their "overseas" counterparts (Prasad, Babbar, \& Motwani, 2001). When developing countries are the target of the research, generally there is a description only of the plants of the developing country (e.g., Fleury, 1999; Karhunen, 2008), or the relationship of the provider on a developing country with their clients from developed countries (e.g., Narayanan, Balasubramanian, \& Swaminathan, 2011). However, we find few studies testing how the variables in strategic operations management vary across different countries (Ahmad \& Schroeder, 2003; Cagliano, Caniato, Golini, Longoni, \& Micelotta, 2011). The lack of comparative OM research reveals an important gap both for research and practice. For example, can an operations manager in AGCO, the global agricultural equipment manufacturer, rely on published research relating environmental performance and financial performance to make decisions to his/her tractor plant in Brazil? Therefore, despite the relevant contribution of the OM literature to the international OM field, it still does not provide evidences of the consistency of operations strategy between countries.

This paper contributes to fill this gap by providing a country comparison of thelevels and the relationships among important variables of operations strategy, such as the competitive priorities, environmental management, green supply management, and organizational learning. Instead of comparing multiple countries, we conducted a careful choice of two countries that allowed us to control many important macroeconomic variables, such as GDP and production output structure.

In section 2, we develop the theory that links our variables and how we expect them to change between countries. We describe our research design and measurement procedures in section 3 . The empirical findings and results are presented in section 4. Finally, in section 5 we present the limitations, managerial implications, future research possibilities, and conclude.

\section{THEORY AND HYPOTHESES}

Figure 1 shows our theoretical model we have replicated from Gavronski, Klassen, Vachon, and Nascimento(2011)andextended byaddingtraditional manufacturing dimensions (Wheelwright, 1984) and the country variable. We draw our hypotheses from the resource-based view of the firm (Barney, 1991; Grant, 1991, 1996): the most basic plant resources, such as the knowledge exchange processes, form lower level capabilities, such as the green management process. The lower level capabilities build higher level capabilities (supply capabilities), such as green supply management (Gavronski et al., 2011). These plant resources and capabilities are then related to plant performance. We add to this framework the institution as a leg of the strategy (Peng, Sunny Li, Pinkham, \& Hao, 2009). From a traditional perspective, the country also plays an important role in the corporate strategy and therefore operations management. According to Porter's Diamond Model a pivotal element for nation's competitiveness is related to factor conditions that are human resources, physical resources, capital resources and infrastructure (Porter, 2011). The institutional environment provided by a country should influence the relationships Resource-Based View (RBV) suggests. Therefore, the country where the plant operates should moderate the relationships between plant resources and plant capabilities, and between plant resources and capabilities and plant performance. 


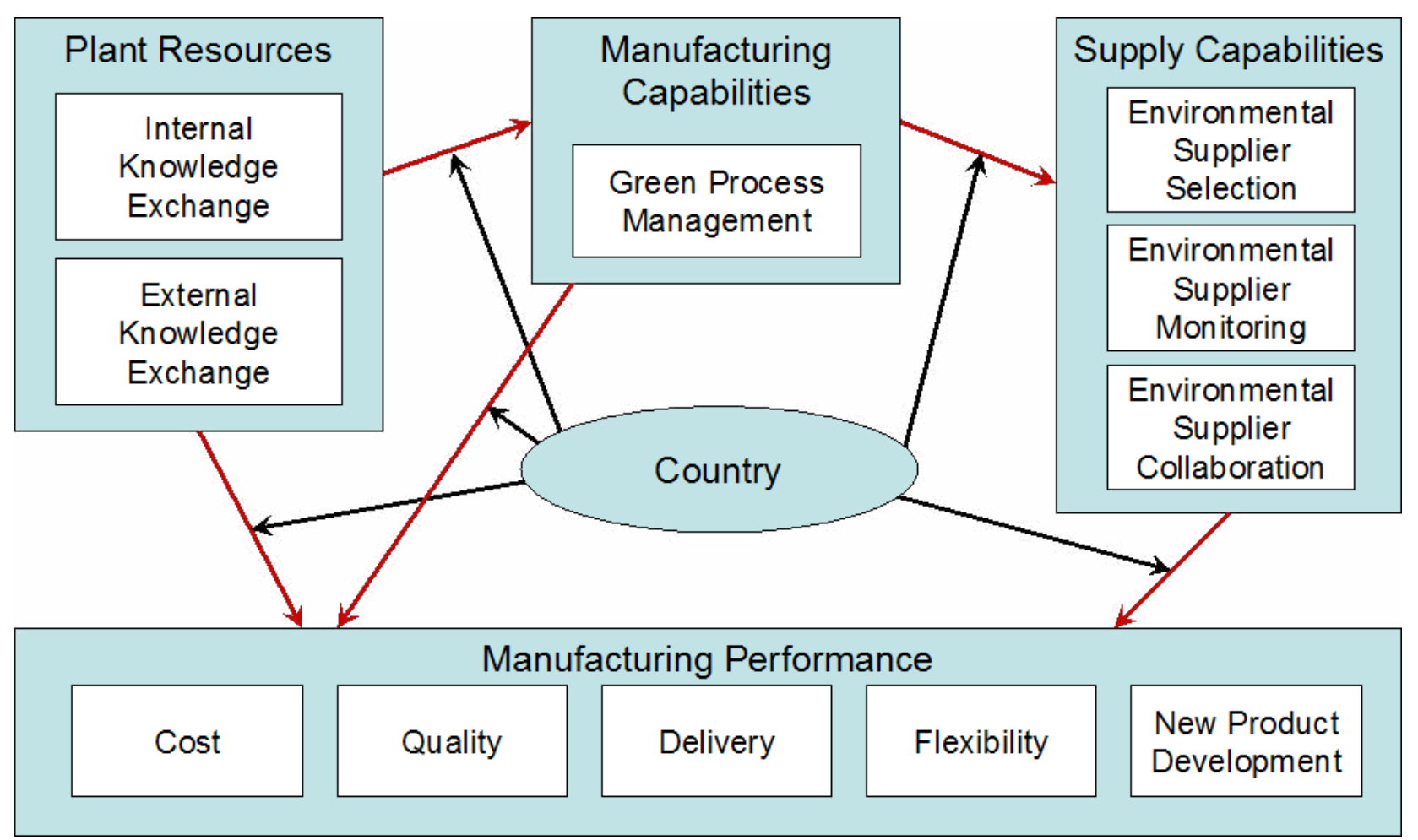

Figure 1: Research model establishing relationship between plant resources, manufacturing capabilities, supply capabilities, and manufacturing performance mediated by country.

\subsection{PLANT RESOURCES}

The knowledge exchange processes are the most basic resources we investigate in this paper. We divide the knowledge exchange processes in internal and external (Paiva, Roth, \& Fensterseifer, 2008). External knowledge exchange is the level of acquisition of new information from outside sources (Cohen \& Levinthal, 1990). Internal knowledge exchange is the level of communication and information exchange, therefore the diffusion of knowledge, inside the plant.

\subsection{MANUFACTURING CAPABILITIES}

We define manufacturing capabilities as the set of physical, financial, human, technological, and organizational resources (Grant, 1991) coordinated by organizational routines (Nelson \& Winter, 1982) and deployed inside a manufacturing plant to improve its manufacturing performance. Because this broad definition could include such disparate practices as lean manufacturing and advanced manufacturing technologies (M. L. Swink \& Nair, 2007), we focus on that particular set of manufacturing capabilities we term green process management.

Green Process Management (GPM) refers to a plant's internal environmental management practices (Zhu, Sarkis, \& Lai, 2008) geared towards improving the plant's environmental performance. GPM can include such activities as design for the environment (DfE), life cycle analysis (LCA), ISO 14001 (Sarkis, 2001), pollution prevention (reduction at the source), pollution control (end-ofpipe technologies), and environmental management systems (EMS) (Klassen \& Whybark, 1999b).

GPM requires an intricate set of soft skills, such as motivating people to dispose of recyclable materials appropriately, and hard technologies, such as wastewater treatment stations. A successful GPM implementation requires both soft skills and hard technologies to work together, and cannot be measured separately. However, soft skills are more dependent of communication, team motivation, and leadership, while hard technologies, especially environmental technologies, are more dependent on external technology suppliers. Therefore, in developed countries, where machinery is cheaper and wages are higher, GPM will be dependent on 
external knowledge exchange and in developing countries, where machinery is costlier and wages are lower, GPM will be dependent on internal knowledge exchange. Moreover, we can expect that, in developed countries, internal knowledge exchange is detrimental to GPM. Team relationship strength, for instance, is negatively related to information search costs (Hansen, Mors, \& Lovas, 2005). Internal knowledge exchange impedes the transfer of complex knowledge (Kathleen M. Eisenhardt \& Santos, 2002). Some authors suggest that a lower level of internal knowledge exchange is, in fact, more effective for some manufacturing capabilities than higher levels of exchange (K. M. Eisenhardt \& Galunic, 2000). Thus we propose the following hypothesis:

Hypothesis 1a. Internal knowledge exchange will be positively associated with green manufacturing capabilities in developing countries.

Hypothesis $1 b$. Internal knowledge exchange will be negatively associated with green manufacturing capabilities in developed countries.

Hypothesis 2a. External knowledge exchange will be negatively associated with green manufacturing capabilities in developing countries.

Hypothesis 2b. External knowledge exchange will be positively associated with green manufacturing capabilities in developed countries.

\subsection{SUPPLY CAPABILITIES}

We define supply management as the complex of mechanisms implemented at the corporate and plant level to assess or improve the performance of a supplier base. This study focuses on the specific practices that industrial buying agents engage in to ensure that suppliers complies appropriately. For most plants, only having good manufacturing capabilities is notenough-itis alsonecessary improve suppliers' performance to have the its performance improved. For example, the carmaker Toyota started the pilot kanban (a lean manufacturing technique) deployment in the decade of 1950. By the decade of 1960, the deployment started in all Toyota's plants. In the decade of 1970, Toyota expanded his kanban methodology to its suppliers (Ohno, 1988).

From all possible supply management initiatives, we focus only on green supply management, which is comprised of three distinct set of activities: environmental selection of suppliers, environmental monitoring of suppliers, and environmental collaboration with suppliers (Gavronski et al., 2011). Environmental selection of suppliers is the inclusion of environmental criteria for selecting potential suppliers. Environmental monitoring of suppliers are the activities conducted by plant employees to ensure current suppliers have adequate levels of environmental performance. Environmental collaboration with suppliers is a set of activities between plant employees and managers and the current supplier base to improve the environmental performance of suppliers. Previous research has shown that green process management mediates the relationship between plant resources and green supply management (Gavronski et al., 2011). However, we have no reason to believe that these relationships would change from developed to developing countries. Therefore, we hypothesize:

H3a. When green process management in a plant increases, the effectiveness of its environmental supplier selection process also increases.

$H 3 b$. When green process management in a plant is at a high level, the environmental supplier monitoring is also high.

H3c. When green process management in a plant is high, environmental supplier collaboration is also high.

\subsection{MANUFACTURING PERFORMANCE}

Manufacturing performance is the ultimate goal of manufacturing strategy. Traditional manufacturing performance dimensions are cost, quality, delivery, and flexibility (Wheelwright, 1984). Newly identified dimensions include innovativeness, or new product development capabilities (M. Swink, Talluri, \& Pandejpong, 2006), environmental performance (Jiménez \& Lorente, 2001), and even social performance.

Manufacturing performance dimensions are linked to manufacturing practices (for a theoretical discussion, see Ketokivi \& Schroeder, 2004). Plants that pursue cutting edge manufacturing practices extend their performance frontiers (Liu, Roth, \& Rabinovich, 2011; Rosenzweig \& Roth, 2004) achieving sustainable competitive advantages (Colotla, Shi, \& Gregory, 2003). Extant literature in OM have linked manufacturing performance with internal and external knowledgeexchange(Ahmad \& 
Schroeder, 2001; Paiva et al., 2008), with green process management (Klassen, 2000; Klassen \& Whybark, $1999 \mathrm{~b}$ ), and with green supply management (Rao \& Holt, 2005; Zhu \& Sarkis, 2004). Consistently with extant literature, we posit that manufacturing resources and capabilities are positively related with manufacturing performance. However, we argue that differences between developed countries and developing countries would change the slope of these relationships. Because developed countries have access to machinery at lower costs, and wages are higher, substantial returns will come from acquisition of technologies, instead of investing time of employees for the internal development of solutions. Therefore, for developed countries, external knowledge exchange will be more related to manufacturing performance than in developing countries, and internal knowledge exchange will be more related to manufacturing performance in developing countries than in developed countries. However, we do not expect a country effect on the relationship between manufacturing performance and green process management or between manufacturing performance and green supply management.

H4a. Manufacturing performance is positively related to internal knowledge exchange in developing countries.

H4b. Manufacturing performance is negatively related to internal knowledge exchange in developed countries.

H5a. Manufacturing performance is negatively related to external knowledge exchange in developing countries.

H5b. Manufacturing performance is positively related to external knowledge exchange in developed countries.

H6. Manufacturing performance is positively related to green process management both in developed and in developing countries.

H7. Manufacturing performance is positively related to green supply management both in developed and in developing countries.

\section{METHODS}

\subsection{RESEARCH SETTING AND DATA}

For country comparison, we have chosen two countries: a developing country and a emergent country. By choosing only two countries, comparing country effects would be easily performed, by including only a dummy variable. Because we would not be allowed to enter more control variables, common in country comparisons, such as GDP (Vachon, 2010), we have carefully chosen two countries comparable: Brazil and Canada. Both countries share many macro-economic commonalities: land size is similar $(8,459,417$ sq. $\mathrm{km}$ vs. 9,093,507 sq. $\mathrm{km}$ ), GDP is similar ( $\$ 2.09$ trillion vs. $\$ 1.57$ trillion), and GDP composition by sector is also quite similar (agriculture: $5.8 \%$ vs. $2.2 \%$, manufacturing: $26.8 \%$ vs. $26.3 \%$, and services: $67.4 \%$ vs. $71.5 \%$ ). Therefore, by comparing manufacturing plantsin these two countries, all thesemacroeconomic variables are controlled. Despite these similarities, Brazil and Canada are very different. With a much larger population, Brazil has a much smaller GDP per capita than Canada $(\$ 10,800$ vs. $\$ 39,400)$ and the inequality of income, measured by the Gini index, is much higher (53.9 vs. 32.1) according to CIA World Factbook (CIA, 2011). Canada, for example, is listed in the Annex B of Kyoto Protocol as one of the developed countries that should reduce greenhouse gas emissions, while Brazil is not. Therefore, Brazil qualifies as a developing country, while Canada is a developed country.

In Canada we conducted preliminary interviews with operation managers from a small sample culled from a larger number of industries in Canada and identified those industries technologically similar and subject to similar customer and government environmental requirements. From this preliminary study, we settled on four industries: metalworking, machinery, electronics and electrical appliances. We then made a stratified random sampling from the Scott's Industrial Database (SID) of manufacturing plants and Canada's National Pollutant Release Inventory (NPRI) database. We followed the expected proportion of the manufacturing plants by industry provided by the Statistics Canada agency. We contacted these companies by phone, checked their addresses, and respondent names. Before sending the questionnaires, we submitted the instrument to a PhD candidate with extensive experience in industry and two professors in the supply management field and solicited suggestions for improvement. We then sent 503 questionnaires, following the Total Design Method (TDM Dillman, 2000) and received 94 usable responses, an 18.7\% response rate, which is close to the recommended 
level, i.e., 20\%, on surveys of this nature (Malhotra \& Grover, 1998). The survey questionnaires were addressed to the plant manager, operations manager, or equivalent decision maker, an approach used by other studies in environmental management and organizational learning and knowledge (Klassen \& Vachon, 2003; Klassen \& Whybark, 1999a).

The data collection in Brazil followed a similar fashion. We have translated the questionnaire to Brazilian Portuguese, and submitted the questionnaire to three managers and one $\mathrm{OM}$ professor, for validation. After validating the translation, we have selected a list of 277 plants extracted from the national industry directory (federation of industries) following the same criteria to build the Canadian dataset. We contacted companies by phone, checked their addresses, and respondent names. We have contacted 277 plants managers following the Total Design Method (TDM Dillman, 2000) and received 46 questionnaires or $16.6 \%$ usable responses, which is similar to the response rate in Canada.

\subsection{MEASUREMENT PROCEDURES}

We used measures for green supply management, green management practices, and knowledge exchange from previously published sources (Gavronski et al., 2011), to ensure validity and reliability. We utilized confirmatory factor analysis to assess the psychometric properties of the questionnaire's scales (CFA - see, e.g. Bollen, 1989). The final model fit for the multi-item scales are in the expected range (Kline, 2005). The reliability, measured by composite reliability, was also above the expected minimum of .7 for both internal and external knowledge exchange. After validating all scales, we converted the raw scores in summated scales by the arithmetic mean of the items of each construct.

For the measurement of manufacturing performance, we asked plant managers to compare their plant performance with competitors, also a customary practice in manufacturing strategy research (Liu et al., 2011).

Plant size was computed taking the natural logarithm of the number of full time employees in the plant.

Country was coded 1 for Brazil and 0 for Canada. For clarity purposes, the variable was termed brazil.
We tested the hypotheses of this paper using multivariate regression with ordinary least squares (OLS) estimation. We used Baron \& Kenny's mediation and moderation tests (1986) to avoid misspecification of the model and inefficient estimation of the effects between organizational resources and green manufacturing capabilities, and from these capabilities to GSM capabilities. However, we are not providing mediation evidence, given that we took all measures at the same time.

Simulations show that the tests we used are the more conservative among those available, thus suggesting fewer Type I errors (MacKinnon, Lockwood, Hoffman, West, \& Sheets, 2002). Baron and Kenny's test is a three-step procedure: first, regressing the mediator on the independent variables; second regressing the dependent variable on the independent variables; and third, regressing the dependent variable on both the mediator and on the independent variables.

Three conditions must hold. First, the independent variables and the mediator must be related in the first regression. Second, the independent and dependent variables must be related in the second regression. Third, the mediator and the dependent variable must be related in the third regression. The mediator is said to perfectly mediate the independent and depend variables if the relation between the latter is not significant when the mediator is controlled. If the coefficient of the independent variable is still significant in the third regression, but it is lower than in the second regression, then the coefficient has a direct and indirect effect on the dependent variable, and the mediator is said to partially mediate the effect.

\section{ANALYSES AND RESULTS}

\subsection{DESCRIPTIVE STATISTICS}

Table 1 reports the means, standard deviations, and correlations of all variables used in this study. Our results showed little correlation between our independent variables, and we expect no concerns for multivariate models. 
Table 1: Descriptive Statistics

\begin{tabular}{|c|c|c|c|c|c|c|c|c|c|c|c|c|c|}
\hline & 1 & 2 & 3 & 4 & 5 & 6 & 7 & 8 & 9 & 10 & 11 & 12 & 13 \\
\hline 1. gpm & - & & & & & & & & & & & & \\
\hline 2. spc & $.44^{\cdots}$ & - & & & & & & & & & & & \\
\hline 3. spm & $35 \cdots$ & $.71^{*}$ & - & & & & & & & & & & \\
\hline 4. $s p s$ & $.42^{-*}$ & $.61^{\circ}$ & $.79^{-\infty}$ & - & & & & & & & & & \\
\hline 5. ike & .15 & .04 & -.02 & .06 & - & & & & & & & & \\
\hline 6. eke & $36^{\cdots}$ & $-40^{m}$ & $.18^{+}$ & $.21^{*}$ & $-45^{m}$ & - & & & & & & & \\
\hline 7. cost & $26=$ & $.25=$ & $26 *$ & $.23 *$ & .14 & $.20^{*}$ & - & & & & & & \\
\hline 8. qual & $27 *$ & .15 & -.06 & .10 & $30^{*}$ & 37 & $.24^{*}$ & - & & & & & \\
\hline 9. delv & $24^{*}$ & .14 & .10 & .14 & $31 \cdots$ & $26^{*}$ & $38 \cdots$ & $28 *$ & - & & & & \\
\hline 10. flex & .08 & .12 & .06 & .11 & $22^{*}$ & $27 *$ & $.23^{*}$ & $32 \cdots$ & $.55 \cdots$ & - & & & \\
\hline 11. nprd & .13 & $.20^{*}$ & .05 & .04 & $37 \cdots$ & .50 & $.16^{+}$ & $-43 \cdots$ & $.38^{* *}$ & $.38 \cdots$ & - & & \\
\hline 12. size & $21^{*}$ & $.27 *$ & 31 & .34 & -.06 & .05 & .10 & .04 & $-19^{*}$ & -.11 & -.05 & - & \\
\hline 13. brazil" & .01 & $.36^{*}$ & 34 & $.23^{*}$ & -.04 & $23^{*}$ & .01 & -.04 & -.01 & .08 & $22^{*}$ & $.30^{*}$ & - \\
\hline Mean & 4.14 & 2.47 & 1.99 & 2.03 & 5.21 & 4.79 & 4.27 & 5.50 & 5.15 & 5.16 & 4.54 & 5.25 & 0.34 \\
\hline SD & 1.25 & 1.42 & 1.30 & 1.30 & 0.99 & 0.99 & 1.20 & 1.03 & 1.30 & 1.15 & 1.56 & 0.92 & 0.47 \\
\hline Range & $1: 7$ & $1: 7$ & $1: 7$ & $1: 7$ & $1: 7$ & $1: 7$ & $1: 7$ & $1: 7$ & $1: 7$ & $1: 7$ & $1: 7$ & & 0:1 \\
\hline
\end{tabular}

Table 2 reports the means, standard deviations, and t-tests of all variables used in this study, by country. On average, Brazilian plants are larger in our sample than the Canadian plants, which differences will be controlled by including size in the estimation of the model.

Table 2: T-tests analysis by country

\begin{tabular}{|c|c|c|c|c|c|}
\hline \multirow[t]{2}{*}{ Country } & \multicolumn{2}{|c|}{ Canada } & \multicolumn{2}{|c|}{ Brazil } & \multirow[b]{2}{*}{ t-test } \\
\hline & Mean & s.d. & Mean & s.d. & \\
\hline gpm & 4.16 & 1.35 & 4.16 & 1.03 & $\begin{array}{l}-0.01 \\
\end{array}$ \\
\hline spc & 2.21 & 1.41 & 2.97 & 1.42 & $-2.95=$ \\
\hline spm & 1.73 & 1.13 & 2.46 & 1.39 & $-3.08 *$ \\
\hline sps & 1.90 & 1.31 & 2.33 & 1.39 & $-1.74^{+}$ \\
\hline ike & 5.23 & 0.96 & 5.18 & 1.05 & 0.28 \\
\hline eke & 4.61 & 0.98 & 5.00 & 0.91 & $-2.36^{*}$ \\
\hline size & 5.01 & 0.88 & 5.60 & 0.79 & $-4.02 \cdots$ \\
\hline cost & 4.23 & 1.13 & 4.27 & 1.30 & -0.16 \\
\hline qual & 5.50 & 1.00 & 5.53 & 1.01 & -0.18 \\
\hline delv & 5.13 & 1.23 & 5.22 & 1.38 & -0.38 \\
\hline flex & 5.17 & 1.18 & 5.36 & 1.12 & -0.93 \\
\hline nprd & 4.46 & 1.54 & 4.98 & 1.47 & $-1.88^{+}$ \\
\hline $\mathbf{N}$ & 94 & & 46 & & \\
\hline
\end{tabular}




\subsection{GREEN PROCESS MANAGEMENT}

We have modeled GPM practices as the dependent variable of the equation. Our models, then, take the form:

GPMi $=\beta_{0}+\beta_{1} \times$ size $+\beta_{2} \times i k e+\beta_{3} \times$ eke $+\beta_{4} \times$ brazil + $\beta_{5} \times i k e: b r a z i l+\beta_{6} \times e k e: b r a z i l++\varepsilon_{i^{\prime}}(1)$

Where size is plant size, ike is the internal knowledge exchange level, eke is the external knowledge exchange level, and brazil is the country variable. Table 3 speaks to the hypotheses $1 \mathrm{a}, 1 \mathrm{~b}, 2 \mathrm{a}$, and $2 \mathrm{~b}$. For model GPM 1, we have constrained $\beta_{2}$ to $\beta_{6}$ to zero. For model GPM 2, we have constrained $\beta_{4}$ to $\beta_{6}$ to zero. Models GPM 1 and GPM 2 are provided for comparison purposes only. Since model GPM 3 provides an interaction of continuous variables (ike and eke) with a categorical variable (brazil), the interpretation of the coefficients is as follows: $\beta_{2}$ is the slope of $i k e$ at brazil=0 (Canadian plants), while $\beta_{5}$ is the change of slope for $i k e$ at brazil=1 (Brazilian plants). Similarly, $\beta_{3}$ is the slope of eke at brazil $=0$ (Canadian plants), while $\beta_{6}$ is the change of slope for eke at brazil=1 (Brazilian plants). As we have predicted, internal knowledge exchange has a positive and significant relationship with GPM in Brazilian plants, while has a negative and significant relationship with GPM in Canadian plants. Therefore, we found support for hypotheses $1 \mathrm{a}$ and $1 \mathrm{~b}$. However, external knowledge exchange, contrary to our expectations, is positively related with green process management for both countries, thus providing support for hypothesis $2 b$, but not for $2 \mathrm{a}$.

Table 3: Green Process Management Model

\begin{tabular}{|c|c|c|c|}
\hline & GPM 1 & GPM 2 & GPM 3 \\
\hline (Intercept) & $2.67^{* *}$ & $1.58^{+}$ & $2.17^{*}$ \\
\hline size & $.28^{*}$ & $24=$ & $.30 *$ \\
\hline ike & & -.14 & $-35^{*}$ \\
\hline eke & & $43^{\cdots+*}$ & $.49^{\cdots}$ \\
\hline brazil $^{2}$ & & & $-2.52^{+}$ \\
\hline ike:brazil & & & $.56^{\circ}$ \\
\hline eke:brazil & & & -.15 \\
\hline $\mathbf{R}^{2}$ & .04 & .13 & .18 \\
\hline$\Delta \mathbf{R}^{2}$ & & .09 & .05 \\
\hline $\mathbf{F}$ & $5.72^{\circ}$ & $6.48 \cdots$ & $4.70 \cdots$ \\
\hline df & 1,133 & 3,130 & 6,127 \\
\hline
\end{tabular}

\subsection{GREEN SUPPLY MANAGEMENT}

We have modeled each set of practices of GSM (collaboration, monitoring, and selection) separately as the dependent variable of the equation. Our models, then, take the form:

GSMi $=\beta_{0}+\beta_{1} \times$ size $+\beta_{2} \times i k e+\beta_{3} \times e k e+\beta_{4} \times g p m+\beta_{5} \times b r a z i l$ $+\beta_{6} \times i k e: b r a z i l++\beta_{7} \times e k e: b r a z i l+\beta_{8} \times g p m: b r a z i l+\varepsilon_{i^{\prime}}$

Where size is plant size, ike is the internal knowledge exchange level, eke is the external knowledge exchange level, gpm is the green process management level, and brazil is the country variable.
Table 4 speaks to the hypotheses $3 a, 3 b$, and $3 c$. For clarity purposes, we have omitted the models with only the control variable, but we have provided the $\Delta R^{2}$ from this model to the models with plant resources (knowledge exchange), which we collectively termed Model 1. For Model 1, we have constrained $\beta_{4}$ to $\beta_{8}$ to zero. For Model 2, we have constrained $\beta_{5}$ to $\beta_{8}$ to zero. By freeing $\beta_{4}$, we are able to evaluate, in the change of $\beta_{2}$ and $\beta_{3}$ from Models 1 to Model 2, whether mediation is occurring. In our mediation tests (Baron \& Kenny, 1986), if $\mathrm{gpm}$ mediates the relationship between ike and GSM and between eke and GSM, coefficients for ike and eke will drop from Model 1 to Model 2. Since Model 3 
provides an interaction of continuous variables (ike, eke, and gpm) with a categorical variable (brazil), the interpretation of the coefficients is as follows: $\beta_{2}$ is the slope of $i k e$ at brazil=0 (Canadian plants), while $\beta 6$ is the change of slope for $i k e$ at brazil=1 (Brazilian plants). Similarly, $\beta_{3}$ is the slope of eke at brazil=0 (Canadian plants), while $\beta_{7}$ is the change of slope for eke at brazil=1 (Brazilian plants), and $\beta 4$ is the slope of gpm at brazil=0 (Canadian plants), while $\beta_{8}$ is the change of slope for gpm at brazil=1 (Brazilian plants). As we have predicted, green process management mediates, at least partially, the relationship between knowledge exchange (both internal and external) and green supply management, for the three dimensions of GSM (collaboration, monitoring, and selection). Also, GPM is positively related to collaboration, monitoring, and selection, thus providing support for hypotheses $3 a, 3 b$, and 3c. The coefficients of the interaction terms are not significant, as we expected. Therefore, there is no country effect in the relationship between green process management and green supply management.

Table 4: Green Supply Management Model

\begin{tabular}{|c|c|c|c|c|c|c|c|c|c|}
\hline \multirow[b]{3}{*}{ (Intercept) } & \multicolumn{3}{|c|}{ Collaboration } & \multicolumn{3}{|c|}{ Monitoring } & \multicolumn{3}{|c|}{ Selection } \\
\hline & Model 1 & Model 2 & Model 3 & Model 1 & Model 2 & Model 3 & Model 1 & Model 2 & Model 3 \\
\hline & -.89 & $-1.62+$ & -1.16 & -.44 & $\begin{array}{l}-1.01 \\
\end{array}$ & -.29 & -81 & $-1.61+$ & $-2.07+$ \\
\hline size & $.34 *$ & $.27^{*}$ & .17 & $.39 *$ & 34 * & $25^{*}$ & $.43 \cdots$ & $36 *$ & $35 *$ \\
\hline ike & $-.29^{*}$ & $-.25^{+}$ & -.22 & -.19 & -.15 & -.24 & -.06 & .00 & .02 \\
\hline eke & $.65^{m-}$ & $51 \cdots$ & $.41 *$ & $.29^{*}$ & .17 & .17 & .19 & .01 & .03 \\
\hline gpm & & $37 \cdots$ & $.42 \cdots$ & & $29^{*}$ & $29=$ & & $.41 \cdots$ & $.48 \cdots$ \\
\hline brazil $^{2}$ & & & .21 & & & -.10 & & & 1.64 \\
\hline ike:brazil & & & -.01 & & & 36 & & & .10 \\
\hline eke-brazil & & & .17 & & & -.27 & & & -.15 \\
\hline gmp:brazil & & & -10 & & & .05 & & & -.29 \\
\hline $\mathbf{R}^{2}$ & .21 & 30 & .33 & .12 & 20 & 26 & .10 & 23 & 25 \\
\hline$\Delta \mathrm{R}^{2}$ & $.15^{b}$ & .09 & .03 & $.05^{b}$ & .07 & .06 & $.01^{b}$ & .12 & .02 \\
\hline $\mathbf{F}$ & $11.32^{m}$ & $13.50^{m}$ & $7.57^{\cdots}$ & $6.13^{m}$ & 7.64 & $5.27^{m}$ & $4.98 *$ & $9.33^{m}$ & $5.08^{m}$ \\
\hline df & 3,129 & 4,125 & 8,121 & 3,130 & 4,126 & 8,122 & 3,131 & 4,127 & 8,123 \\
\hline
\end{tabular}

\section{MANUFACTURING PERFORMANCE}

We have modeled each dimension of manufacturing performance (cost, quality, delivery, flexibility, and new product development - NPD) separately as the dependent variable of the equation. Our models, then, take the form:

Performance $_{i}=\beta_{0}+\beta_{1} \times$ size $+\beta_{2} \times i k e+\beta_{3} \times$ eke $+\beta_{4} \times g p m+$ $\beta_{5} \times s p c+\beta_{6} \times s p m+$

$+\beta_{7} \times$ sps $+\beta_{8} \times$ brazil $+\beta_{9} \times i k e: b r a z i l++\beta_{10} \times$ eke:brazil $+\beta_{11} \times$ gpm:brazil $+\beta_{12} \times$ spc:brazil $+\beta_{11} \times$ spm:brazil + $\beta_{11} \times$ sps:brazil $+\varepsilon_{i^{\prime}}$

Where size is plant size, ike is the internal knowledge exchange level, eke is the external knowledge exchange level, gpm is the green process management level, spc is the level of environmental supplier collaboration, spm is the level of environmental supplier monitoring, sps is the level of environmental supplier selection, and brazil is the country variable. Table 5 speaks to the hypotheses $4 a, 4 b, 5 a, 5 b, 6$, and 7 . For clarity purposes, we have omitted the models with only the control variable. For Model 1, we have constrained $\beta_{8}$ to $\beta_{11}$ to zero. For Model 2, we have all coefficients unconstrained. Since Model 3 provides an interaction of continuous variables (ike, eke, gpm, spc, spm, and sps) with a categorical variable (brazil), the interpretation of the coefficients follows the same rules as the previous models. We only found support for hypothesis $4 \mathrm{a}$ in model Quality 2, where ike is positively related to quality performance for Brazilian plants. Contrary to our expectations, we found delivery and new product development performances to be positively related to internal knowledge exchange, both in Brazilian and in Canadian plants. Therefore, we found no support for hypothesis $4 \mathrm{~b}$. We found 
support for hypotheses $5 \mathrm{a}$ and $5 \mathrm{~b}$ for quality and flexibility performances, which are negatively related to external knowledge exchange in Brazilian plants and positively related in Canadian plants. New product development performance, however, is positively related to external knowledge exchange for both countries, which contradicts hypothesis $5 \mathrm{a}$ and supports hypothesis $5 \mathrm{~b}$. Contrary to our expectations, green process management is not related to performance in all plants. Only quality performance in Brazilian plants is positively related to green process management. Therefore, we found no support for hypothesis 6 . Finally, contrary to our expectations, environmental monitoring of suppliers is negatively related to quality performance in both countries, and the other estimates for green supply management are not significant. Therefore, we found no support for hypothesis 7 .

Table 5: Manufacturing Performance Model

\begin{tabular}{|c|c|c|c|c|c|c|c|c|c|c|}
\hline & Cost 1 & Cost 2 & Quality 1 & Quality 2 & Delivery 1 & Delivery 2 & Flexibility 1 & Flexibility 2 & NPD 1 & NPD 2 \\
\hline (Intercept) & $1.77^{*}$ & $1.98+$ & $2.84^{* *}$ & $3.38^{* *}$ & 3.51 & $396^{\circ}$ & 4.37 & 4.55 & .74 & 93 \\
\hline size & .07 & .08 & .06 & .08 & $-.32 *$ & $-33^{*}$ & -.19 & $-.21+$ & -.13 & -.21 \\
\hline ike & .14 & .15 & $.17+$ & -.02 & $.34^{*}$ & .27 & .13 & .05 & $.31 *$ & $37^{*}$ \\
\hline eke & .10 & .08 & $.22^{*}$ & $.41=$ & .13 & .13 & $.23^{+}$ & $.35^{*}$ & $.66 \cdots$ & $63 \cdots$ \\
\hline gpm & .13 & .07 & $.14^{+}$ & .00 & .17 & .21 & -.04 & -.13 & -.05 & -.12 \\
\hline $\mathbf{s p c}$ & .03 & .11 & .09 & .12 & .00 & -.01 & .00 & -.10 & .06 & .19 \\
\hline spm & .19 & .26 & $-32=$ & $-.40^{*}$ & .09 & .11 & -.04 & .12 & .03 & -.07 \\
\hline sps & -.05 & -.16 & .13 & $.23+$ & .01 & -.09 & .14 & .20 & -.09 & -.06 \\
\hline brazil $^{a}$ & & -1.21 & & -.53 & & -.95 & & .56 & & 1.14 \\
\hline ike:brazil & & -.12 & & $.51^{*}$ & & .25 & & .36 & & -.13 \\
\hline eke:brazil & & .17 & & $-.71 *$ & & -.05 & & $-.67^{*}$ & & -.16 \\
\hline gmp:brazil & & .23 & & $.40^{*}$ & & -.08 & & .36 & & 39 \\
\hline spc:brazil & & -.19 & & -.01 & & .08 & & .30 & & -.42 \\
\hline spm:brazil & & -.29 & & .05 & & -.29 & & $-.65^{+}$ & & .13 \\
\hline sps:brazil & & .45 & & -.19 & & 39 & & .10 & & .03 \\
\hline $\mathbf{R}^{2}$ & .13 & .17 & .23 & .32 & .19 & .21 & .10 & .18 & .28 & 33 \\
\hline$\Delta \mathbf{R}^{2}$ & & .04 & & .09 & & .02 & & .08 & & .05 \\
\hline $\mathbf{F}$ & $2.40^{*}$ & 1.52 & 4.82 & 3.62 & 4.03 & 2.18 & $1.80^{+}$ & $1.67+$ & $6.60 \cdots$ & $3.86 \cdots$ \\
\hline df & 7,114 & 14,107 & 7,114 & 14,107 & 7,119 & 14,112 & 7,115 & 14,108 & 7,117 & 14,110 \\
\hline
\end{tabular}

\section{DISCUSSION AND CONCLUSIONS}

\subsection{RESEARCH IMPLICATIONS}

This paper provides a country comparison of the levels and the relationships among important variables of operations strategy, such as the competitive priorities, environmental management, green supply management, and organizational learning. To accomplish these objectives, we conducted a survey in a developing country and a developed country, namely Brazil and Canada, and compared results using multivariate hierarchical regression analysis.

Our research replicates and extends previous research (Gavronski et al., 2011). We found that for the Brazilian plants, where machinery is costlier and wages are lower, internal knowledge exchange plays a key-role in deploying manufacturing capabilities, such as green process management. Canadian plants, on the other hand, have access to machinery at lower costs, but wages are higher. In these plants, internal knowledge exchange is detrimental to the deployment of green process management. However, for both countries, external knowledge exchange is positively related to green process management. One possible explanation for this result is the dual characteristic of green process management: it depends on soft skills as well as hard technologies, and most plants do not have the required resources to develop everything internally. Given that most green technologies require special knowledge, such as advice and scanning of environmental laws and regulations, pollution control technologies, etc., external knowledge exchange is an important driver of green process management, both in developed and developing countries. 
Manufacturing capabilities are positively related to supply capabilities. Our research provides empirical evidence of this relationship, using the case of green process management and green supply management. Given the anecdotal evidence those manufacturing capabilities are built before supply capabilities, our results also allow us to speculate that manufacturing capabilities mediate supply capabilities. We found as well evidence that this relationship is country invariant, therefore providing generalizability to the RBV-based claim that higher-order capabilities are built over lowerlevel capabilities (Teece, Pisano, \& Shuen, 1997).

Our research also shows that the relationship between resources, capabilities, and performance are more intricate than we previously expected. For example, while we did not found any evidence relating cost performance and plant resources and capabilities, we found resources and capabilities to be related to the other manufacturing performance dimensions. Internal knowledge exchange, for instance, is positively related to delivery and new product development performances, regardless of the country of operation. This result is contrary to our expectations, but consistent with results of research with data collected from either developed countries (Schroeder, Bates, \& Junttila, 2002) or developing countries (Paiva et al., 2008). We found the expected relationships for both quality and flexibility performances, which are positively related to external knowledge exchange in Canadian plants and negatively related to external knowledge exchange in Brazilian plants. Again, one possible explanation is that Canadian plants rely more on machinery (therefore, external sources of knowledge) to improve and sustain quality and flexibility, while Brazilian plants rely more on internal resources, either because of the costs of machinery or the relatively lower costs of labor. Finally, we found no relationship between performance and green process management and green supply management. These results suggest that most basic resources, such as knowledge exchange (internal and external), are related to manufacturing performance, higherlevel capabilities, such as the ones we tested, are linked to other dimensions of performance, such as marketing or financial, or linked to manufacturing performance indirectly, by means of other variables.

\subsection{MANAGERIAL IMPLICATIONS}

We demonstrate that country of operation of the plant matters for manufacturing strategy formulation. When deploying a technology that can be achieved either by hard technology or by softer skills of employees, operations managers in developed countries will prefer the former, and should emphasize the external knowledge exchange in the plant, but operations managers in developing countries will prefer the latter, and should emphasize the internal knowledge exchange. When deploying a technology that requires the acquisition of machinery or very specialized knowledge, operations managers should emphasize the external knowledge exchange of the plant, regardless of the country of operation.

We also find that, depending on the competitive priorities operations managers want to prioritize in their plants, the country of operation can be important. For example, for achieving quality or flexibility performances, operations managers in developed countries should emphasize external knowledge exchange, but operations managers in developing countries can find that external knowledge exchange is detrimental to quality or flexibility. For new product development performance, both internal knowledge exchange and external knowledge exchange should be developed. These examples show that performance objectives can be either trade-offs or cumulative (Ferdows \& De Meyer, 1990; Rosenzweig \& Roth, 2004; Skinner, 1992), depending on the country of operation.

\subsection{LIMITATIONS}

Given the empirical nature of this research, it is important to highlight its limitations. First, we examined only a few industries and had only a modest response rate, thus the generalizability of our results is limited. Moreover, the data collection in Brazil is still in progress, so the results should be considered preliminary.

Second, we collected data from only one source inside the organization: the plant manager. This narrow range of respondents can cause problems with common method variance (Podsakoff, MacKenzie, Lee, \& Podsakoff, 2003). This specific group of respondents, however, is the most knowledgeable for the type of decision we are investigating. Third, we propose a model that demands robust mediation tests, particularly with panel data, and our evidence is taken from a crosssectional survey. Therefore, these results should be considered preliminary. However, we did test our data with widely accepted mediation methods, and 
the results do not disconfirm our theory, a sign that further investigation should consider testing our model in other research designs.

Forth, we employed a 7-point Likert scale that has some limitation as a continuous scale. Despite some literature claims there is no influence of the number of scale points in the validity and reliability of scales (Weng, 2004), recent studies show otherwise. Aguinis, Pierce, \& Culpepper (2009) point out the influence of scale coarseness in correlations (and, ultimately, in CFA and OLS estimates) showing that there is attenuation in the correlation. A 7-point Likert scale, as we have done, would imply attenuation in the correlations by a factor of .970 . By using this attenuation factor, our results would more conservative, by $3 \%$. However, because our fit results and p-values are already above the recommended minimum, and we are not using the results for prediction, only for testing the existence of a relationship, we believe the results will not be biased.

Finally, the largest models tested 14 independent variables, with sample sizes ranging from 122 to 132 cases. This is below the recommended 10:1 cases to variables ratio, but above the minimum 5:1 ratio (Hair, Anderson, Tatham, \& Black, 1998).

\subsection{MAIN CONTRIBUTIONS}

A key contribution of this paper is to highlight the importance of taking country of operation into consideration in manufacturing strategy research and practice. While country effects have been accounted for in previous research (Ahmad \& Schroeder, 2003; Cagliano et al., 2011; Vachon, 2010), the results were either country-level data (as opposed to our study, which analyzes plant-level data) or used country only as a control variable, not as a substantive independent variable. Moreover, the opportunity to replicate and extended a previous research provide a greater assurance of the theory proposed. According to Carter (2004) replication studies are an important component of mature discipline, thus study of this nature provide new insights and pave way for further research.

\subsection{FUTURE RESEARCH}

Peng and colleagues suggested that strategy sits on a tripod formed by resources and capabilities, industry, and institutional forces (Peng et al., 2009). While we accounted for resources and capabilities, and institutions, future research should consider the industry effect into manufacturing strategy, not only controlling by industry standard codes, but by industry variables, such as the bargain power of suppliers and clients, concentration of industry, relative size to competitors, etc.

While we used multiple regression to test our hypotheses, future research could deploy hierarchical linear models (e.g., Kull \& Wacker, 2010) to test a wider range of countries and incorporate covariates at country-level, such as GDP, education, cost of labor, taxes, or ind ustry-level covariates, such as the aforementioned variables, for more accurate estimates. Last, given the cross-sectional nature of the data, future research should test the mediation hypothesis with a longitudinal design.

\section{REFERENCES}

Ahmad, S., \& Schroeder, R. G. (2001). THE IMPACT OF ELECTRONIC DATA INTERCHANGE ON DELIVERY PERFORMANCE. Production and Operations Management, 10(1), 16-30. doi: 10.1111/ j.1937-5956.2001.tb00065.x

Ahmad, S., \& Schroeder, R. G. (2003). The impact of human resource management practices on operational performance: recognizing country and industry differences. Journal of Operations Management, 21(1), 19.

Barney, J. (1991). Firm Resources and Sustained Competitive Advantage. Journal of Management, 17(1), 99-120.

Baron, R. M., \& Kenny, D. A. (1986). The moderatormediator variable distinction in social psychological research: Conceptual, strategic, and statistical considerations. Journal of Personality and Social Psychology, 51(6), 1173-1182.

Bollen, K. A. (1989). Structural equations with latent variables: Wiley New York.

Cagliano, R., Caniato, F., Golini, R., Longoni, A., \& Micelotta, E. (2011). The impact of country culture on the adoption of new forms of work organization. International Journal of Operations E Production Management, 31(3), 297-323. doi: 10.1108/01443571111111937

Carter, C. R. (2004). Purchasing and Social Responsibility: A Replication and Extension. 
Journal of Supply Chain Management, 40(4), 4.

Chakravarty, A. K., Ferdows, K., \& Singhal, K. (1997). Global Operations and Technology Management: A Note from the Editors of the Special Issue. Production and Operations Management, 6(2), 99101. doi: 10.1111/j.1937-5956.1997.tb00417.x

Cohen, W. M., \& Levinthal, D. A. (1990). Absorptive Capacity: A New Perspective on Learning and Innovation. Administrative Science Quarterly, 35(1), 128-152.

Colotla, I., Shi, Y. J., \& Gregory, M. J. (2003). Operation and performance of international manufacturing networks. International Journal of Operations $\mathcal{E}$ Production Management, 23(10), 1184-1206. doi: 10.1108/01443570310496625

Dillman, D. A. (2000). Mail and Internet Surveys: The Taylored Design Method. New York: Wiley.

Eisenhardt, K. M., \& Galunic, D. C. (2000). Coevolving: At last, a way to make synergies work. Harvard Business Review, 78(1), 91-102.

Eisenhardt, K. M., \& Santos, F. M. (2002). Knowledge-Based View: A New Theory of Strategy? In A. Pettigrew, H. Thomas \& R. Whittington (Eds.), Handbook of Strategy and Management. London: Sage.

Ferdows, K., \& De Meyer, A. (1990). Lasting improvements in manufacturing theory: in search of a new theory. Journal of Operations Management, 9, 168-183.

Fleury, A. (1999). The changing pattern of operations management in developing countries - The case of Brazil. International Journal of Operations $\mathcal{E}$ Production Management, 19(5-6), 552-564. doi: 10.1108/01443579910260874

Gavronski, I., Klassen, R. D., Vachon, S., \& Nascimento, L. F. M. d. (2011). A resource-based view of green supply management. Transportation Research Part E: Logistics and Transportation Review, 47(6), 872-885. doi: 10.1016/j.tre.2011.05.018

Grant, R. M. (1991). The Resource-Based Theory of Competitive Advantage: Implications for Strategy Formulation. California Management Review, 33(3), 114-135.
Grant, R. M. (1996). Toward a knowledge-based theory of the firm. Strategic Management Journal, 17((Special Issue)), 109-122.

Hair, J. F., Anderson, R. E., Tatham, R. L., \& Black, W. C. (1998). Multivariate data analysis (5. ed.). Upper Saddle River, N.J.: Prentice Hall.

Hansen, M. T., Mors, M. L., \& Lovas, B. (2005). Knowledge sharing in organizations: Multiple networks, multiple phases. Academy of Management Journal, 48(5), 776-793.

Jiménez, J. d. B., \& Lorente, J. J. C. (2001). Environmental performance as an operations objective. International Journal of Operations $\mathcal{E}$ Production Management, 21(12), 1553-1572.

Karhunen, P. (2008). Managing international business operations in a changing institutional context: The case of the St. Petersburg hotel industry. Journal of International Management, 14(1), 28-45. doi: 10.1016/j.intman.2007.02.007

Ketokivi, M., \& Schroeder, R. (2004). Manufacturing practices, strategic fit and performance: A routine-based view. International Journal of Operations \& Production Management, 24(2), 171191. doi: 10.1108/01443570410514876

Klassen, R. D. (2000). Exploring the linkage between investment in manufacturing and environmental technologies. International Journal of Operations $\mathcal{E}$ Production Management, 20(2), 127-147.

Klassen, R. D., \& Vachon, S. (2003). Collaboration and evaluation in the supply chain: the impact on plant-level environmental investment. Production and Operations Management, 12(3), 336.

Klassen, R. D., \& Whybark, D. C. (1999a). Environmental management in operations: The selection of environmental technologies. Decision Sciences, 30(3), 601-631.

Klassen, R. D., \& Whybark, D. C. (1999b). The impact of environmental technologies on manufacturing performance. Academy of Management Journal, 42(6), 599-615.

Kline, R. B. (2005). Principles and practice of structural equation modeling (2nd ed.). New York: Guilford Press. 
Kull, T. J., \& Wacker, J. G. (2010). Quality management effectiveness in Asia: The influence of culture. Journal of Operations Management, 28(3), 223-239. doi: 10.1016/j.jom.2009.11.003

Liu, N., Roth, A. V., \& Rabinovich, E. (2011). Antecedents and consequences of combinative competitive capabilities in manufacturing. International Journal of Operations \& Production Management, $\quad 31(12), \quad$ 1250-1286. doi: $10.1108 / 01443571111187448$

MacKinnon, D. P., Lockwood, C. M., Hoffman, J. M., West, S. G., \& Sheets, V. (2002). A comparison of methods to test mediation and other intervening variable effects. Psychological Methods, 7(1), 83104.

Malhotra, M. K., \& Grover, V. (1998). An assessment of survey research in POM: from constructs to theory. Journal of Operations Management, 16(4), 407.

Narayanan, S., Balasubramanian, S., \& Swaminathan, J. M. (2011). Managing Outsourced Software Projects: An Analysis of Project Performance and Customer Satisfaction. Production and Operations Management, 20(4), 508-521. doi: 10.1111/j.19375956.2010.01162.x

Nelson, R. R., \& Winter, S. G. (1982). An evolutionary theory of economic change. Cambridge, Mass.: Belknap Press of Harvard University Press.

Ohno, T. (1988). Toyota production system: beyond large-scale production. Cambridge, Mass.: Productivity Press.

Paiva, E. L., Roth, A. V., \& Fensterseifer, J. E. (2008). Organizationalknowledgeand themanufacturing strategy process: A resource-based view analysis. Journal of Operations Management, 26, 115-132.

Peng, M. W., Sunny Li, S., Pinkham, B., \& Hao, C. (2009). The Institution-Based View as a Third Leg for a Strategy Tripod. [Article]. Academy of Management Perspectives, 23(3), 63-81. doi: 10.5465/amp.2009.43479264

Podsakoff, P. M., MacKenzie, S. B., Lee, J.-Y., \& Podsakoff, N. P. (2003). Common method biases in behavioral research: A critical review of the literature and recommended remedies. Journal of Applied Psychology, 88(5), 879-903.
Porter, M. E. (2011). Competitive advantage of nations: creating and sustaining superior performance: Free press.

Prasad, S., Babbar, S., \& Motwani, J. (2001). International operations strategy: current efforts and future directions. International Journal of Operations \& Production Management, 21(5-6), 645665. doi: 10.1108/01443570110390381

Radjou, N., \& Kaipa, P. (2010). Do multinationals really understand globalization? BusinessWeek. Retrieved from http://www.businessweek.com/ globalbiz/content/aug2010/gb2010086_282527. htm

Rao, P., \& Holt, D. (2005). Do green supply chains lead to competitiveness and economic performance? International Journal of Operations $\mathcal{E}$ Production Management, 25(9/10), 898.

Rosenzweig, E. D., \& Roth, A. V. (2004). Towards a Theory of Competitive Progression: Evidence from High-Tech Manufacturing. Production and Operations Management, 13(4), 354-368. doi: 10.1111/j.1937-5956.2004.tb00223.x

Roth, A. V., Gray, A. E., Singhal, J., \& Singhal, K. (1997). International Technology and Operations Management: Resource Toolkit for Research and Teaching. Production and Operations Management, 6(2), 167-187. doi: 10.1111/j.1937-5956.1997. tb00424.x

Sarkis, J. (2001). Manufacturing's role in corporate environmental sustainability: Concerns for the new millennium. International Journal of Operations \& Production Management, 21(5/6), 666.

Schroeder, R. G., Bates, K. A., \& Junttila, M. A. (2002). A resource-based view of manufacturing strategy and the relationship to manufacturing performance. Strategic Management Journal, 23(2), 105-117.

Skinner, W. (1992). Missing the links in manufacturing strategy. In C. A. Voss (Ed.), Manufacturing Strategy: Process and Content (pp. 13-25). London: Chapman \& Hall.

Swink, M., Talluri, S., \& Pandejpong, T. (2006). Faster, better, cheaper: A study of NPD project efficiency and performance tradeoffs. Journal of Operations Management, 24(5), 542-562. doi: 10.1016/j.jom.2005.09.004 
Swink, M. L., \& Nair, A. (2007). Capturing the competitive advantages of AMT: Designmanufacturing integration as a complementary asset. Journal of Operations Management, 25(3), 736-754.

Teece, D. J., Pisano, G., \& Shuen, A. (1997). Dynamic capabilities and strategic management. Strategic Management Journal, 18(7), 509-533.

Vachon, S. (2010). International Operations and Sustainable Development: Should National Culture Matter? Sustainable Development, 18(6), 350-361. doi: 10.1002/sd.398

Wheelwright, S. C. (1984). Manufacturing Strategy: Defining the Missing Link. Strategic Management Journal, 5(1), 77-91.

Zhu, Q., \& Sarkis, J. (2004). Relationships between operational practices and performance among early adopters of green supply chain management practices in Chinese manufacturing enterprises. Journal of Operations Management, 22(3), 265.

Zhu, Q., Sarkis, J., \& Lai, K.-h. (2008). Green supply chain management implications for "closing the loop". Transportation Research Part E: Logistics and Transportation Review, 44(1), 1-18. 


\section{AUTHOR'S BIOGRAPHY}

Vitor Fabian Brock: Master in Administration, concentration: Operations Management (2012). Bachelor in International Business (2008). Alma mater: Universidade do Vale do Rio dos Sinos - Unisinos. Member of Academy of Management (AoM); Production and Operations Management Society (POMS) and European Operations Management Society (EurOMA)

Iuri Gavronski: $\mathrm{PhD}$ in Business Administration from the Federal University of Rio Grande do Sul UFRGS (2009), Master's degree in Business Administration from Unisinos (2003) and Bachelor in Business Administration from Porto Alegre School of Business Administration and Accounting Sciences - FAPA (1999). Member of Academy of Management (AoM), Strategic Management Society (SMS) and Production and Operations Mana 